\title{
Doença inflamatória intestinal: qual a relevância da doença no Brasil?
}

O termo doença inflamatória intestinal (DII) engloba doenças como a retocolite ulcerativa idiopática (RCUI) e a doença de Crohn (DC) que se caracterizam por serem recorrentes e imunologicamente mediadas cujo órgão alvo é o intestino e o evento principal é o processo inflamatório crônico.

A etiologia é desconhecida, provavelmente multifatorial. Preconiza-se que indivíduos com predisposição genética ao interagirem com fatores ambientais, prováveis gatilhos da doença, desencadeiem uma resposta imunológica descontrolada originando um processo inflamatório crônico intestinal. Na progressão da doença podem surgir perfurações, obstruções e até tumores intestinais. As poucas modificações evolutivas da DII com o tratamento e o surgimento em indivíduos jovens tendem a provocar grande impacto na capacidade laborativa, qualidade de vida e nos aspectos sócio-econômicos dos pacientes e familiares.

A prevalência da DII rapidamente aumentou nos países industrializados na segunda metade do século XX, tendendo a se estabilizar. A incidência da DC é de 5 casos/100 mil habitantes/ano nos Estados Unidos e Europa, com uma prevalência de 50/100 mil, enquanto na RCUI, esta é de 12/100 mil habitantes nos Estados Unidos.

Nos países em desenvolvimento, nos quais o estilo de vida ocidental vem ocorrendo, tais taxas estão em ascensão e apontam para a influência ambiental na gênese da DII. As taxas de prevalência, incidência e mortalidade no Brasil ainda são desconhecidas, apesar de relatos regionais descreverem um aumento no número de casos novos de DC, se comparados ao de RCUI.

Acomete preferencialmente indivíduos na 2ạ a 3a décadas e apresenta espectro diverso de sintomas, gravidade e manifestações extraintestinais. O quadro clínico mais freqüente inclui diarréia crônica, dor abdominal e sangramento retal, que também ocorrem em doenças prevalentes no Brasil, como nas infecções intestinais bacterianas, parasitárias ou virais. Dificuldades diagnósticas surgem tanto na formulação da hipótese clínica como no processo de investigação. A inexistência de um exame único, padrão ouro, torna necessária a associação de dados clínicos, exames sorológicos, radiológicos, endoscópicos e histológicos para a realização do diagnóstico. Mesmo com o uso de todo este aparato, o diagnóstico pode não ocorrer e somente a evolução natural da doença poderá nos auxiliar.

A cura ainda é inexistente, mas o surgimento de novas drogas biológicas acena para a redução da morbidade da DII por intermédio do controle de células e de mediadores imunológicos envolvidos na inflamação, impedindo a sua perpetuação. Entretanto, o uso crônico e oneroso das drogas acarreta importante impacto sócio-econômico para o Sistema Único de Saúde que libera medicação para cerca de 12 mil pacientes.

Com o objetivo de analisar o impacto da DII na saúde publica brasileira, verificamos a inexistência de: coleta sistematizada de informações sobre os dados clínicos dos pacientes nos principais centros de referência, estimativas de prevalência e incidência no Brasil, acompanhamento de coortes de pacientes a longo prazo, avaliações econômicas de custos diretos (exames, drogas, serviços médicos, hospitalizações) e indiretos (aposentadorias precoces, absenteísmo) gerados pela doença. Neste contexto criou-se o Grupo Brasileiro de Estudos de Doenças Inflamatórias formado por especialistas que visa promover a realização de estudos epidemiológicos, realizar um consenso nacional sobre DII com normatizações diagnósticas e terapêuticas e auxiliar a flexibilização dos órgãos governamentais no que se refere à liberação de medicações para tratamento da DII, que gerarão uma melhoria no atendimento do paciente.

Cyrla Zaltman

Faculdade de Medicina, Universidade Federal do Rio de Janeiro, Rio de Janeiro, Brasil.

c.zaltman@gmail.com 